\title{
Investigation of Windage Splits in an Enclosed Test Fixture Having a High Speed Composite Rotor in Low Air Pressure Environments
}

\author{
H-P. Liu, M.D. Werst, and J.J. Hahne \\ Center for Electromechanics \\ The University of Texas at Austin \\ Austin, TX 78712
}

\author{
D. Bogard \\ Department of Mechanical Engineering \\ The University of Texas at Austin \\ Austin, TX 78712
}

\begin{abstract}
The University of Texas at Austin Center for Electromechanics (UT-CEM) has designed and conducted a series of composite rotor spin tests to measure the windage losses and temperature distributions of a test setup at high rotor speeds and low air pressures. The intent of the windage tests is to validate the windage loss predictions and investigate how the airgap windage is distributed between the rotor and stator. The findings of the spin tests will then be used to perform windagerelated thermal design and analysis of a high speed electrical machine.
\end{abstract}

The radial air-gap flows under the test conditions, a low rotor cavity air pressure of 1 torr and high rotor surface velocities of $333 \mathrm{~m} / \mathrm{s}$ and $614 \mathrm{~m} / \mathrm{s}$, were in a laminar flow regime. Transient rotor and stator finite element thermal analyses, using the measured windage losses and predicted laminar-flow windage splits, have been carried out to analyze the rotor and stator temperature distributions. This paper shows the detailed thermal analysis and compares the predictions with the measurements. The predicted and measured transient rotor and stator temperatures are in good agreements.

Keywords-windage, high speed composite rotor, low air pressure

\section{INTRODUCTION}

Pulsed power rotating electrical power supplies in modern mobile systems typically use high strength graphite epoxy composite materials in rotor and stator designs. High rotor tip speeds and lightweight machine structures are essential to high energy storage densities demanded by mobile weapon applications. Given the large amount of energy stored in these high speed rotating machines, overheating of the rotor outer and stator inner surface composite materials of a continuous duty alternator is likely if the frictional windage losses generated in the air gaps between the rotating and stationary components become excessive and can't be diffused and removed effectively. Composite materials lose their strength as the epoxy resins soften at elevated temperatures and machine's structural integrity degrades significantly as a result.

Manuscript received December 19, 2004. This paper was previously published in the IEEE Proceedings of the 2004 12th Symposium on Electromagnetic Launch Technology. This research was sponsored by the U.S. Army Research Laboratory through Lockheed-Martin Missile and Fire Control under contract number 4300050944.
Windage drag in a rotating machine is largely dependent on its rotor tip velocity and the magnitude of air pressure in the air gaps. A high-speed rotor is typically designed to be operated in a partial vacuum environment to reduce windage drag such that the composites will not be overheated under a steady-state operating condition. However, practical limits on the rotating seals and vacuum pump capacities determine the achievable vacuum level in a mobile high speed rotating system. Partial vacuum operation generally necessitates a non-ventilated rotor cooling design in which the generated windage losses must be somehow divided between the rotor outer and stator inner surfaces and diffuse through the composites that have low transverse thermal conductivities. To perform a challenging thermal design of a high speed and high energy density rotating power supply, the analytical abilities of accurately predicting windage losses and windage splits between rotor and stator become very important.

Windage investigations have been conducted in the past to determine the windage losses in rotating machines [1-4], primarily with rotor tip velocities lower than $350 \mathrm{~m} / \mathrm{s}$ tested at air pressure levels near the atmospheric pressure. Windage test data for high-speed rotors in partial vacuum environments are generally not available. The University of Texas at Austin Center for Electromechanics (UT-CEM) has designed and conducted a series of composite rotor spin tests to measure the windage losses and temperature distributions of a test setup at high rotor speeds and low air pressures [5,6]. The intent of the windage tests is to validate the windage loss predictions [7] and investigate how the air-gap windage is distributed between the rotor and stator under the test conditions. The findings of the composite rotor spin tests will then be used to perform integrated rotor, stator, and air-gap windage thermal analyses of high speed rotating electrical machines.

Transient rotor and stator thermal finite element analyses (FEA), using the measured windage losses and predicted windage splits, have been carried out to analyze rotor and stator temperature distributions. In this paper, detailed comparisons between the predicted and measured temperature distributions are made to evaluate the analytical windage split predictions. 


\section{AIR-GAP FLOW CHARACTERIZATION}

The annular gap flow between concentric cylinders with a rotating inner cylinder and a stationary outer cylinder is commonly referred as a Couette flow, which results from a steady and relative motion of two parallel surfaces that are separated by a fluid. The flow regimes associated with a walldriven air-gap flow are very complicated and dependent on the magnitudes of the air pressure, air temperature, air gap dimension, and rotor speed. In general, the flow can be categorized as a continuum flow, slip flow, transition flow, and free molecule flow, depending on the degree of rarefaction present. Relatively speaking, the density levels of the continuum, slip, and free molecule flows are ordinary, slightly or moderately rarefied, and highly rarefied. The division of a flow into various flow regimes is based on the value of Knudsen number, which is a dimensionless parameter defined by the ratio of molecular mean free path over air gap dimension. The mean free path of a gas flow is the average distance traveled by a gas molecule between collisions.

The classical continuum flow of a linear Newtonian viscous fluid described by the Navier-Stokes momentum equations, derived by assuming the fluid as a continuous medium in which the viscous shear stresses are linearly proportional to the strain rates, represents the limiting case that the Knudsen number is negligibly small everywhere in the flow field. To solve for the shear stress, the Navier-Stokes equations impart zero-slip flow boundary conditions at the interfaces between the fluid and the solid.

As the air pressure in the air gap drops below the continuum flow limit, a rarefied gas flow occurs when the mean free path is no longer small or becomes relatively large compared to the air gap dimension. For a slightly or moderately rarefied gas flow, or the so-called slip flow, intermolecular and molecule-surface collisions are of equal importance, and the velocity and temperature of the air in the immediate neighborhood of the solid walls are different from those of the rotor and stator surfaces. The air appears to slip on the solid surfaces and introduces velocity and temperature discontinuities at the interfaces between the air and the boundary surfaces.

For a highly rarefied free molecule flow, the mean free path is at least several times greater than the air gap dimension and the flow field is entirely undisturbed by the presence of the boundary surfaces. Molecular collisions in the region between solid surfaces are negligible and the flow phenomena are governed by the molecule-surface interaction. The momentum and energy transfer occur solely from direct encounters between the gas molecules and the wall surfaces.

\section{AIR-GAP WINDAGE SPLIT ANALYSIS}

To determine how the windage heat losses are divided between the rotating and stationary boundary surfaces in a continuum air-gap Couette flow, simultaneous solutions of the momentum and energy conservation equations of the boundary layer are required. The momentum differential equation governs the velocity field and the energy differential equation governs the temperature field. These governing differential equations can be solved to obtain velocity and temperature distributions of the air in the air gap by applying appropriate hydraulic and thermal boundary conditions. Finally, the Fourier's law of conduction is used to calculate the heat fluxes on the boundary surfaces.

To derive a closed-form solution for windage loss distribution in a continuum Couette flow between two concentric circular cylinders with one of which rotates at a constant speed about its axis, certain simplifying assumptions need to be made. The cylinders are assumed to be very long in comparison with their diameters so that the air-gap flow field is two-dimensional. For a typical rotating electrical machine, the size of radial air gap is very small as compared to the radii of the rotor and stator. Therefore, the radial air-gap flow can be approximately modeled by a flow confined between two parallel flat plates. One of these plates moves with a constant velocity of $U$ and the other plate remains stationary. Without having external pressure gradient, the driving mechanism of the gap flow is the plate movement in the $\mathrm{x}$ direction. The flow is also assumed to be a steady laminar flow having constant fluid properties, such as viscosity and thermal conductivity. The moving and stationary plates are assumed to have different constant temperatures of $T_{r}$ and $T_{s}$, respectively. As a result of a temperature difference between the plates, there will be heat conduction across the gap fluid.

Under a steady-state condition, the only forces acting on a fluid element in a Couette flow are the viscous shear forces. Applying no-slip velocity boundary conditions on both the boundary plates to the momentum conservation equation of the gap flow, a linear flow velocity profile is obtained as follows:

$$
\mathrm{u}=\left(\frac{U}{L}\right) \mathrm{y}
$$

where $\mathrm{u}$ is a local fluid velocity at a position $\mathrm{y}$ located between the plates, $U$ is the velocity of the moving plate, and $L$ is the separation distance between the plates. Performing an energy balance analysis on a control volume of the laminar boundary layer flow, the net result becomes

$$
\mathrm{k} \frac{d^{2} T}{d y^{2}}+\mu\left(\frac{d u}{d y}\right)^{2}=0
$$

where $\mathrm{k}$ is the fluid thermal conductivity, $\mu$ is the fluid dynamic viscosity, and $\mathrm{T}$ is the air-gap fluid temperature which is a function of the radial location in the air gap. Equation (2) is a steady one-dimensional heat conduction equation with a viscous dissipation of $\mu(d u / d y)^{2}$ as a heat source. Substituting equation (1) into equation (2) and applying thermal boundary conditions after integration, the gap fluid temperature distribution can be expressed as follows [8]:

$$
\frac{T_{s}-T}{T_{s}-T r}=\frac{y}{L}\left[1-\frac{\mu U^{2}}{2 k\left(T_{s}-T r\right)}\left(1-\frac{y}{L}\right)\right]
$$

For air-gap windage split calculation in a rotating electrical machine, equation (3) can be used to calculate the wall shear stresses based on the air temperature gradients at the air-tosolid interfaces if the rotor and stator boundary surface temperatures are provided. The application of equation (3) is 
restricted to a continuum steady laminar Couette flow with constant fluid properties.

\section{WINDAGE TESTS}

To understand the effect of operating high-speed rotors in a partial vacuum, a series of spin tests, consisting of a composite rotor which is capable of being spun up to $900 \mathrm{~m} / \mathrm{s}$, have been designed and tested $[5,6]$. These spin tests were designed to simulate pulse alternator rotor-to-stator conditions. Direct measurements of windage drag were made using a stator torque sensor. Spin tests have been performed in low pressure environments with air gap air pressure levels at 10 torr, 1 torr, and 0.1 torr. Three peak rotor tip velocities, $333 \mathrm{~m} / \mathrm{s}(15,000$ $\mathrm{rpm}), 614 \mathrm{~m} / \mathrm{s}(27,600 \mathrm{rpm})$, and $892 \mathrm{~m} / \mathrm{s}$ (40,000 rpm) were selected for the windage tests. The intent of these windage tests was not only to validate the analytical windage predictions in different flow regimes, but also to investigate how the windage losses were distributed between the rotor and stator at the selected rotor peak velocities. The spin tests provided good windage drag measurements and the analytically predicted transient windage losses agreed well with the measured windage losses at all three pressure levels [7].

The windage tests were conducted at Test Devices Inc. (TDI) of Hudson, Massachusetts. After each windage test, the spin pit was opened and the assembly was cooled for two hours to bring the rotor and stator temperatures back to approximately room temperature before the next test could be conducted. However, it was later found that, even after 2-hour cooling, the initial rotor and stator temperature distributions for the next test were quite non-uniform and the temperatures could differ by 5 to $10^{\circ} \mathrm{C}$. The non-uniform rotor and stator initial temperature distributions made it very difficult to compare the predicted and measured temperatures such that accurate and useful windage split information could be obtained. To determine windage loss distributions between the rotor and stator, transient thermal FEA on two tests, 15,000 rpm at 1 torr and 27,600 rpm at 1 torr, were performed since uniform initial temperatures were observed in these two tests, which were conducted either after a short check-out test or at the beginning of a particular test date.

Fig. 1 shows a sectional view of the test rotor and stator. Fig. 2 shows the thermocouple installation in the stator assembly for stator temperature measurement. Fig. 3 shows the infrared sensor installation in the stator assembly for rotor surface temperature measurement. These infrared sensors were positioned to be flush with the inner surfaces of the stator G-10 liners. The infrared sensor's accuracy was specified for a target emissivity of 0.9. The actual rotor composite rim surface emissivity, measured by Thermophysical Properties Research Laboratories (TPRL), was 0.882. After the windage tests, the infrared sensors were calibrated at UT-CEM by allocating the rotor and stator assembly in an oven with various stator temperature environments. The temperatures measured by the infrared sensors positioned in the warm stator were compared to the temperatures recorded by thermocouples attached to the rotor rim surface. The conclusion from this calibration test was that the infrared sensors provided correct surface temperature measurements even when the stator surface temperatures were much higher than the rotor surface temperatures. The correspondence between the middle infrared sensor and the rotor surface thermocouple was always within $1 \mathrm{C}$, and within $0.2^{\circ} \mathrm{C}$ if the temperature differential between the stator and rotor was $20 \mathrm{C}$ or less . No correction of the infrared sensor output was warranted. It was concluded that the infrared sensors have reliably measured the rotor surface temperatures during the windage tests conducted at TDI.

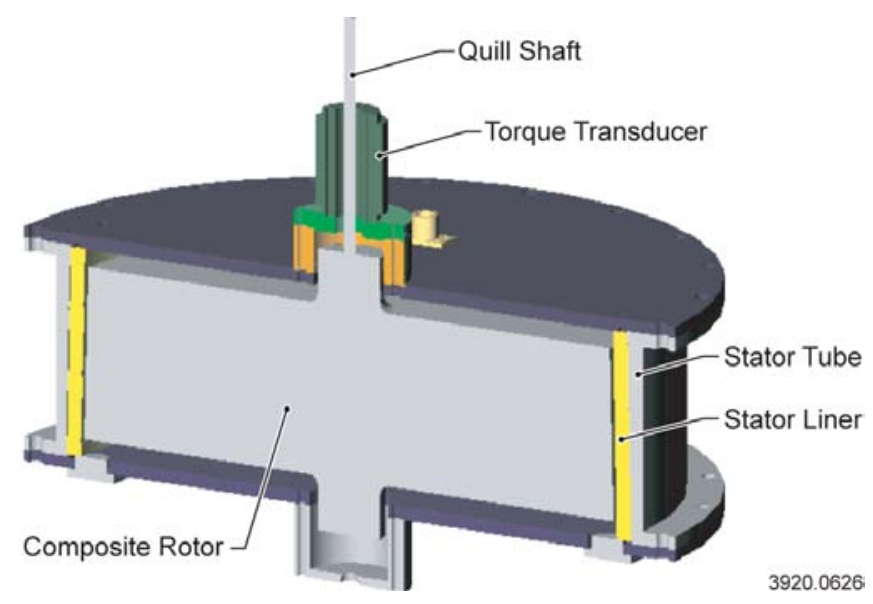

Figure 1. Section view of windage experiment test hardware

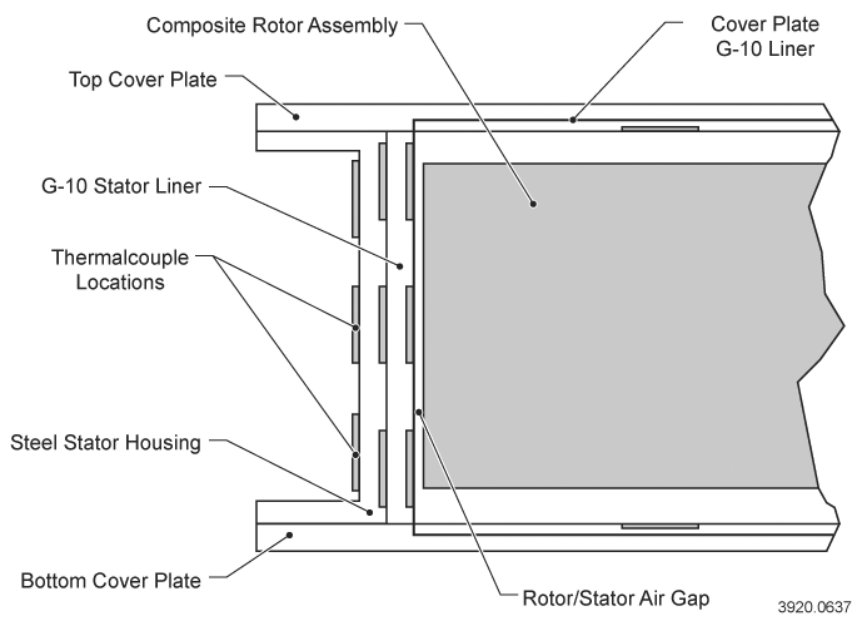

Figure 2. Thermocouple installation in stator assembly 


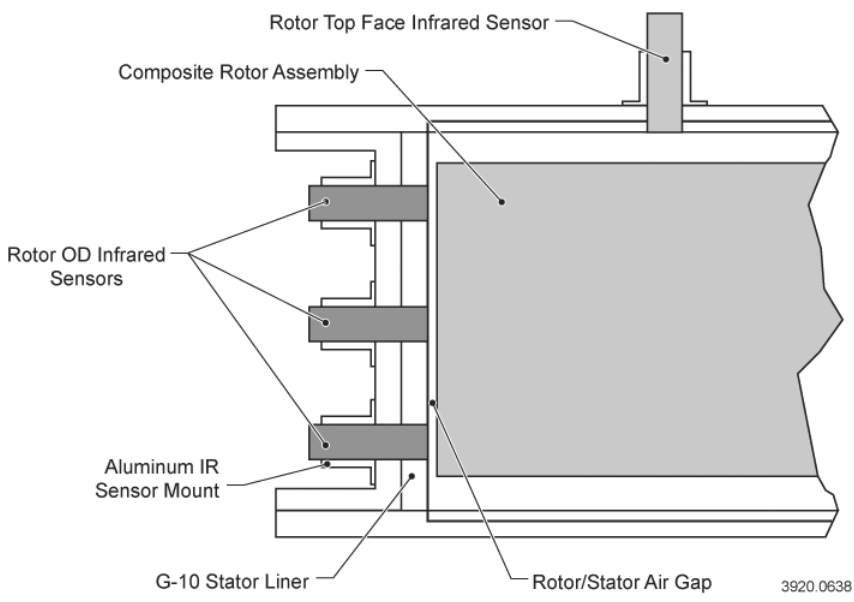

Figure 3. Infrared sensor installation in stator assembly

\section{TRANSIENT THERMAL ANALYSIS}

The axisymmetric FEA thermal model mesh is shown in Fig. 4, in which the locations for temperature comparison between the analysis and test results are indicated. It was found from the FEA analysis that the predicted temperature differentials across the stator steel tube were much smaller than those measured. The thermal FEA assumed a perfect interfacial contact between the outer-diameter (OD) surface of the stator G-10 liner and the inner-diameter (ID) surface of the steel tube. However, in the windage test assembly, the stator G-10 liner was machined to have a line-to-line fit with the bore of the steel tube. It was apparent that a contact thermal resistance existed at the interface between these two dissimilar materials and this contact resistance was aggravated by a lack of interface contact pressure. An interfacial material with a thickness of $0.051 \mathrm{~cm}$ (0.020 in.) and a low thermal conductivity of $0.05 \mathrm{~W} / \mathrm{m} / \mathrm{K}$ was therefore added in between the stator G-10 liner and steel tube in the FEA model to better match the measured temperature drop across the steel tube.

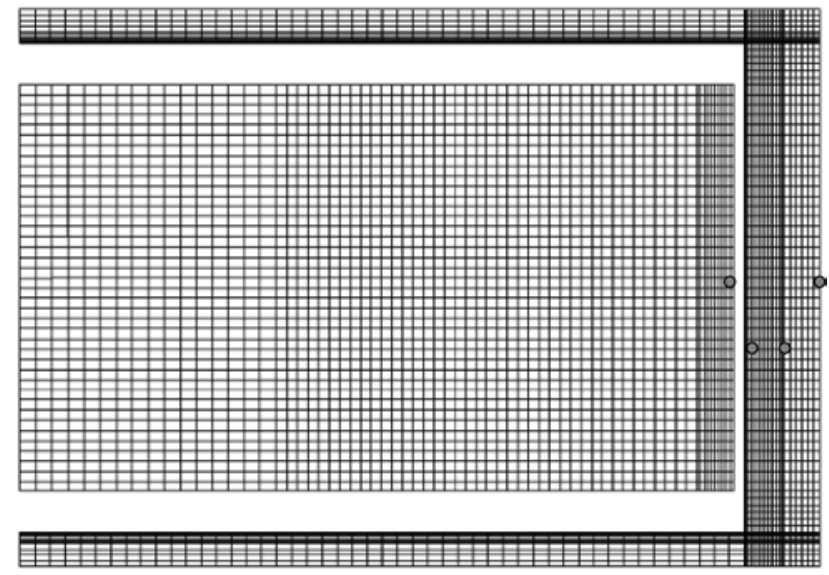

oLocations for temperature comparison between analysis and test results
For the conducted windage tests, the partition between the continuum and slip flows was analytically calculated to be around 2 torr, which was in line with the predictions of a separate Computational Fluid Dynamics (CFD) analysis [9]. The CFD analysis predicted that the air velocity and temperature slip slightly at the rotor and stator surfaces ( $1 \%$ to $2 \%$ slip) at a rotor cavity pressure of 1 torr. Although the two tests being analyzed were designed to be carried out at a 1-torr air pressure level in the spin pit, the actual measured air pressures in the radial air gaps were somewhat higher due to additional centrifugal pressure rises. The measured transient rotor speeds, spin-pit pressures, radial air-gap pressures of these two tests are plotted in Figs. 5 and 6. Equation (3) was used to calculate the rotor-stator windage splits of these two windage tests, where continuum laminar flows or near continuum laminar flows in the radial air gaps were observed, and the results are summarized in table I. The predicted windage splits in the radial air gaps for both tests are close to a $50 \%-50 \%$ even windage split between the rotor and stator.

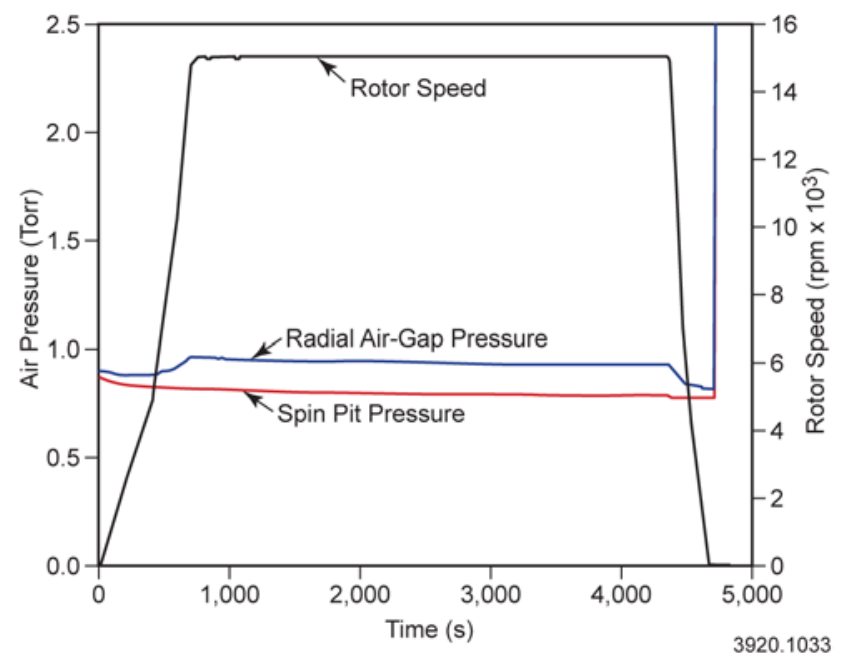

Figure 5. Transient rotor speed and air pressures during test (15,000 rpm / 1 torr)

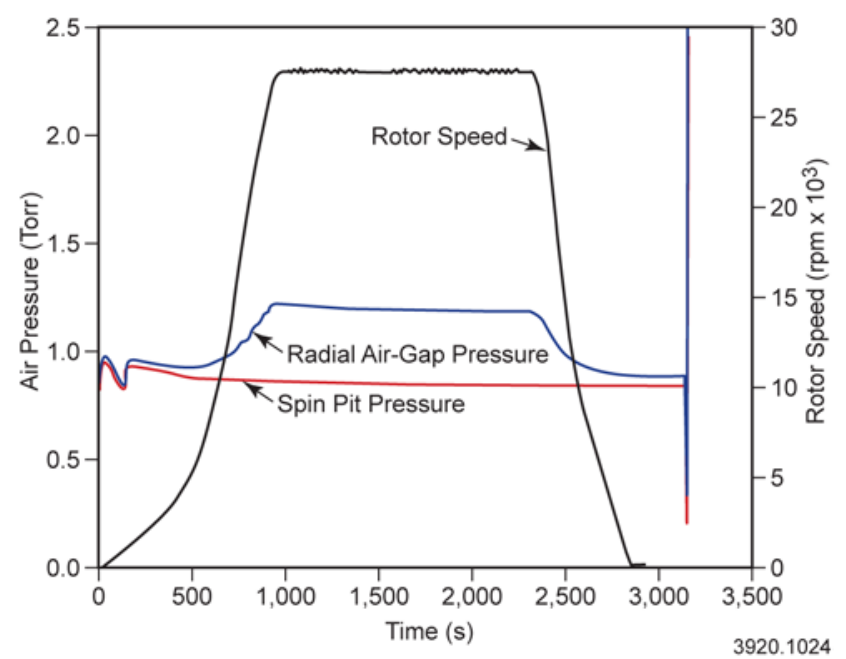

Figure 6. Transient rotor speed and air pressures during test (27,600 rpm / 1 torr) 
TABLE I. ANALYTICAL PREDICTIONS OF WINDAGE SPLITS IN TWO WINDAGE TESTS

\begin{tabular}{|c|c|c|c|c|c|}
\hline $\begin{array}{l}\text { Windage } \\
\text { Test } \\
\text { Conditions }\end{array}$ & $\begin{array}{l}\text { Rotor } \\
\text { Speed } \\
(\mathrm{m} / \mathrm{s})\end{array}$ & $\begin{array}{c}\text { Measured } \\
\text { Rotor OD } \\
\text { Temp } \\
\left({ }^{\circ} \mathrm{C}\right)\end{array}$ & $\begin{array}{l}\text { Measured } \\
\text { Stator ID } \\
\text { Temp } \\
\left({ }^{\circ} \mathrm{C}\right)\end{array}$ & $\begin{array}{l}\text { Avg. } \\
\text { Radial Air } \\
\text { Gap Air } \\
\text { Temp. } \\
\left({ }^{\circ} \mathrm{C}\right)\end{array}$ & $\begin{array}{c}\text { Predicted } \\
\text { Rotor- } \\
\text { Stator } \\
\text { Windage } \\
\text { Split }\end{array}$ \\
\hline $\begin{array}{l}15,000 \mathrm{rpm} \\
\text { and } 1 \text { torr }\end{array}$ & 333 & 47.8 & 48.1 & 54 & $\begin{array}{l}50.4 \%- \\
49.6 \%\end{array}$ \\
\hline $\begin{array}{l}27,600 \mathrm{rpm} \\
\text { and } 1 \text { torr }\end{array}$ & 614 & 72.0 & 80.0 & 98 & $\begin{array}{l}53.1 \%- \\
46.9 \%\end{array}$ \\
\hline
\end{tabular}

Detailed analysis conditions and assumptions of the transient thermal FEA are summarized as follows:

- $\quad$ Measured windage losses used

- Predicted windage loss contributions from radial and axial air gaps used

- $\quad$ Predicted radius-dependent windage loss distributions in axial air gaps used

- Radiation heat transfer across rotor/stator air gaps modeled

- Radiation heat transfer between stator exterior surfaces and spin pit interior wall modeled

- TPRL measured temperature-dependent material thermal properties used

- A constant 50\%-50\% even windage splits between rotor and stator

- A calculated thermal contact resistance, a 0.051-cm thick contact layer with a thermal conductivity of 0.05 $\mathrm{W} / \mathrm{m} / \mathrm{K}$, between the stator G-10 liner OD and stator steel tube ID surfaces included in the FEA model

- $\quad$ Spin pit interior wall temperature of $25^{\circ} \mathrm{C}$

- Based on the initial thermal conditions of the tests, the initial rotor and stator temperatures assigned in FEA differ slightly in each test

A 50\%-50\% even windage split between the rotor and stator was assumed during the entire test duration of the two tests being analyzed. The predicted transient temperature distributions and comparisons between the predicted and measured transient temperatures at selected locations (shown in Fig. 4) are included in Figs. 7 to 12. The transient temperature plots show good agreements between the predicted and measured temperatures for both windage tests.
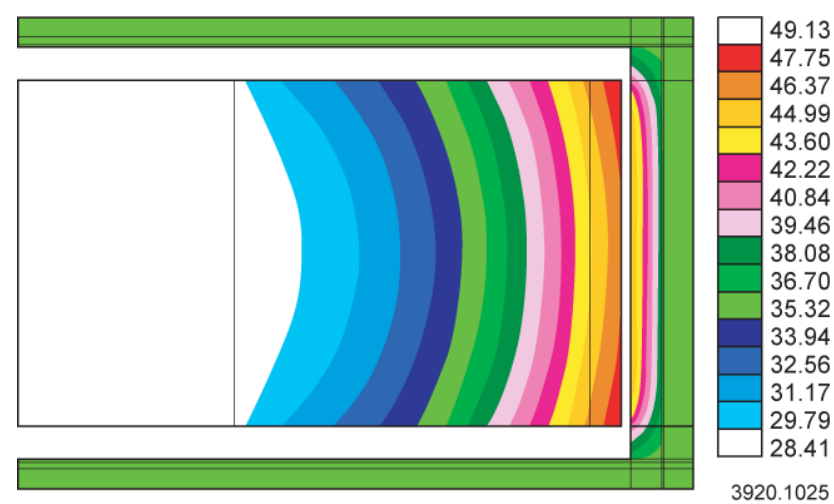

Figure 7. Rotor and stator temperature distributions $\left({ }^{\circ} \mathrm{C}\right)$ at time $=4,350 \mathrm{~s}$ (maximum transient temperatures, 15,000 rpm / 1 torr)

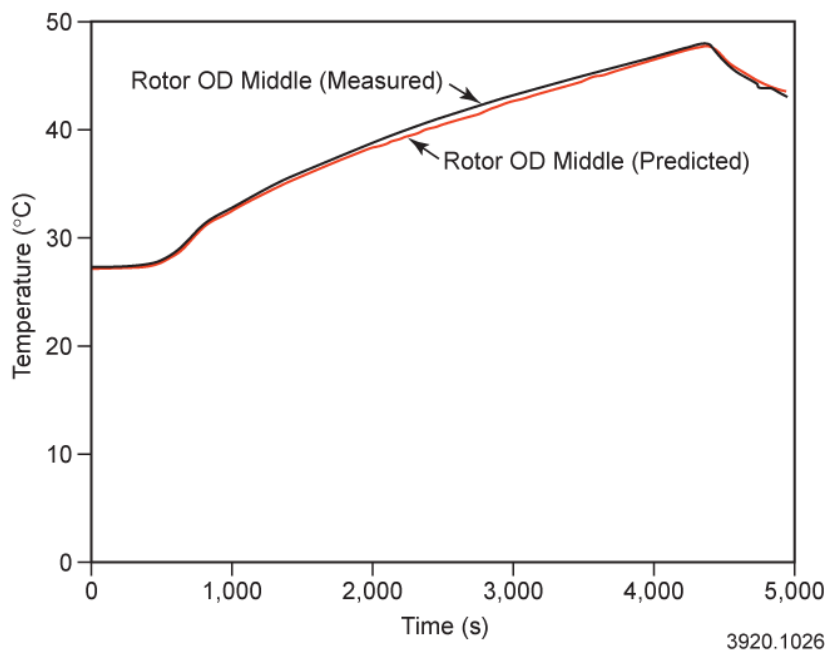

Figure 8. Measured and predicted rotor OD transient temperatures (15,000 rpm /1 torr)

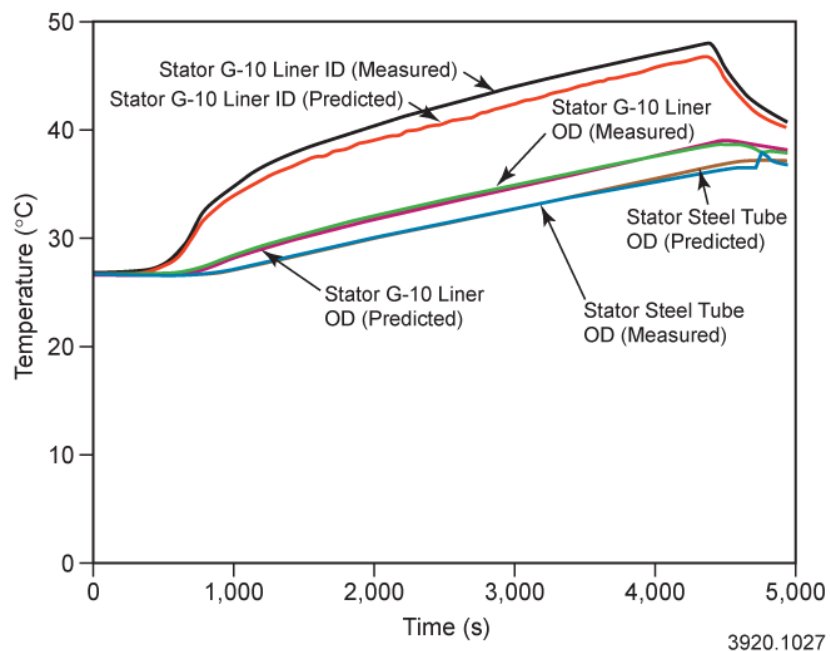

Figure 9. Measured and predicted stator transient temperatures (15,000 rpm/1 torr)

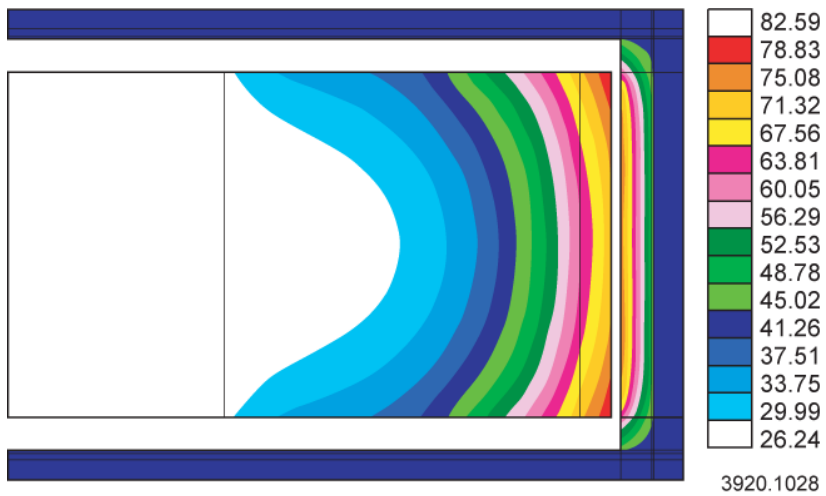

Figure 10. Rotor and stator temperature distributions $\left({ }^{\circ} \mathrm{C}\right)$ at time $=2,340 \mathrm{~s}$ (maximum transient temperatures, 27,600 rpm / 1 torr) 


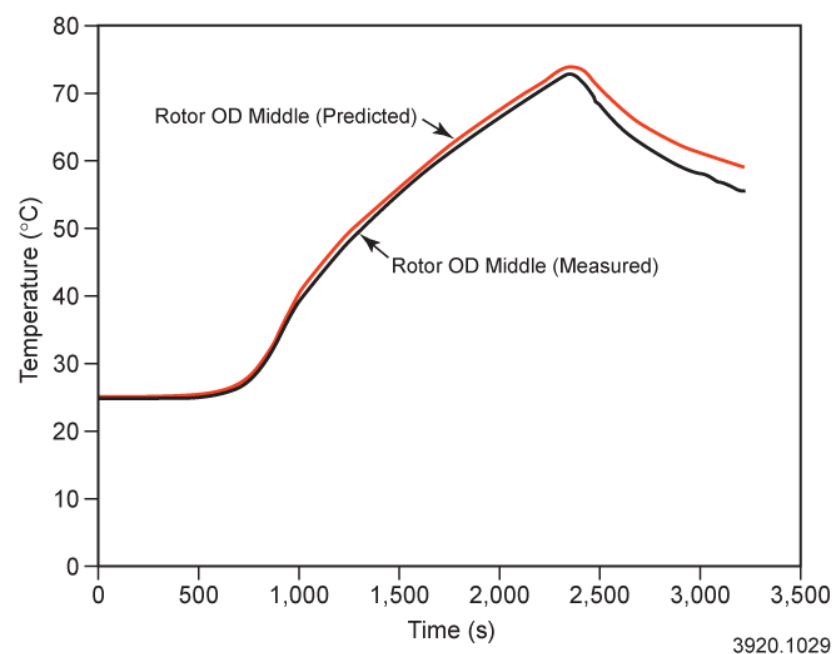

Figure 11. Measured and predicted rotor OD transient temperatures (27,600 rpm / 1 torr)

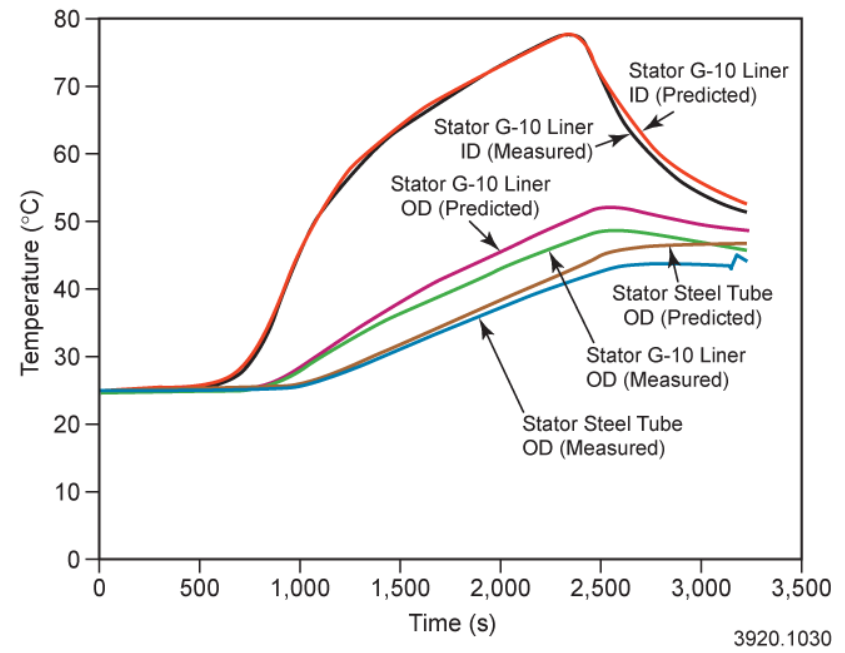

Figure 12. Measured and predicted stator transient temperatures (27,600 rpm / 1 torr)

\section{CONCLUSION}

For a continuum laminar Couette flow, a closed-form airgap air temperature distribution formula exists and can be used to predict windage loss distributions if rotor and stator surface temperatures are provided. Based on a 50\%-50\% even windage split between the rotor and stator, the FEA predicted transient rotor and stator temperatures agreed well with those being measured in two windage tests conducted at an air pressure level of 1 torr and rotor peak velocities of $333 \mathrm{~m} / \mathrm{s}$ and $614 \mathrm{~m} / \mathrm{s}$.
The approximate even windage split demonstrated in these two windage tests is primarily due to the similar rotor OD and stator ID temperatures which are the results of the absence of other cooling and heating mechanisms, except the windage heating, and similar thermal diffusion rates in the test rotor and stator material during the windage tests. However, in most of the rotating electrical machine operations, uneven windage splits between rotor and stator are very likely because the electrical heating, active cooling, and material thermal properties of these two components can be quite different.

The analytical windage split prediction described in this paper is limited to continuum laminar Couette flows having constant fluid properties. As the flows become non-laminar at high rotor speeds or high air pressures or become noncontinuum at low air pressures, CFD analyses could be performed to investigate the flow behavior in the air gaps to predict fluid velocity distributions, fluid temperature distributions, and windage splits for known boundary temperatures.

\section{ACKNOWLEDGMENT}

This research was sponsored by the U.S. Army Research Laboratory through Lockheed-Martin Missile and Fire Control under contract number 4300050944.

\section{REFERENCES}

[1] J. E. Vrancik, "Prediction of Windage Power Loss in Alternators," NASA Technical Note D-4849, October 1968.

[2] H. Zimmermann, A. Firsching, G. H. Dibelius, and M. Ziemann, "Friction Losses and Flow Distribution for Rotating Disks With Shielded and Protruding Bolts," ASME Transactions, Journal of Engineering for Gas Turbines and Power, vol. 108, pp. 547-552, July 1986.

[3] D. G. McLaren, and H. J. Leutheusser, "Hydrogenerator Windage Loss," ASME General Papers in Fluids Engineering, vol. 127, pp. 9-13, 1991.

[4] E. B. Durkin, and J. J. Schauer, "Windage Power Loss of High-Speed Generators," Proceedings of the ASME Advanced Energy Systems Division, AES-Vol. 3, 1997.

[5] M. D. Werst, J. J. Hahne, H-P. Liu, and C. E. Penney, "Design of High Speed Test Rotors for Pulse Alternator Component Development,” IEEE Transactions on Magnetics, Vol 39, No. 1, January 2003

[6] J. J. Hahne, M. D. Werst, C. E. Penney, H-P. Liu, and D. Bogard, "Measurement of Windage Losses and Temperature Distribution for a High Speed Composite Rotor in a Stator Assembly at Low Air Pressures," 2003 ASME Summer Heat Transfer Conference, Las Vegas, Nevada, July 20-23, 2003.

[7] H-P. Liu, M. D. Werst, J. J. Hahne, and D. Bogard, "Prediction of Windage Losses of an Enclosed High Speed Composite Rotor in Low Air Pressure Environments," 2003 ASME Summer Heat Transfer Conference, Las Vegas, Nevada, July 20-23, 2003.

[8] A. F. Mills, Heat Transfer, Irwin, Boston, 1992.

[9] K. Marr, and D. B. Goldstein, Low-Density Simulations of Flow between Rotating Coaxial Cylinders, A summary of CFD analysis using Direct Simulation Monte Carlo Method, Department of Aerospace Engineering and Engineering Mechanics, University of Texas at Austin, 2002. 